\title{
Prevalence of Vitamin D deficiency among pregnant women and effect of Vitamin D supplementation on maternal and fetal outcomes: A double-blind randomized placebo controlled trial
}

\author{
Neelam Aggarwal ${ }^{1}$, Rimpi Singla ${ }^{2}$, Usha Dutta ${ }^{3}$, Sanjay Kumar Bhadada ${ }^{4}$, Sourabh Dutta ${ }^{5}$, \\ Lakhbir Dhaliwal ${ }^{6}$, Sukant Garg ${ }^{7}$
}

${ }^{1}$ Professor, ${ }^{2}$ Associate Professor, ${ }^{6}$ Ex-Professor and Head, Department of Obstetrics and Gynaecology, ${ }^{3}$ Professor, Department of Gastroenterology, ${ }^{4}$ Professor, Department of Endocrinology, ${ }^{5}$ Professor, Department of Neonatology, Post Graduate Institute of Medical Education and Research, Chandigarh, ${ }^{7}$ Associate Professor, Department of Pathology, HSJ Institute of Dental Sciences, Punjab University, Chandigarh, India

Background: Vitamin D deficiency (VDD) in pregnancy has been found to be associated with adverse outcome in various observational studies. Evidence from randomized control trials is necessary to change current recommendations. Aims and Objectives: We conducted randomized controlled trial to assess the effect of Vitamin D supplementation on pregnancy outcome. We also looked for predictors of VDD as universal testing is neither recommended nor available. Materials and Methods: Consecutive pregnant women at 12-16 weeks of gestation were invited to participate in the study. Eligible women were assessed for potential risk factors for VDD (serum concentration $<20 \mathrm{ng} / \mathrm{dl}$ ). Serum $25-\mathrm{OH}$ Vitamin D levels were checked. At 20 weeks gestation, consenting women $(n=297)$ were randomized to receive either 60,000 IU Vitamin $D(n=151)$ orally daily for 5 days or placebo $(n=146)$. Maternal and fetal outcomes were compared between the two groups by intention-to-treat analysis. Results: Out of 304 eligible women, $92 \%$ had VDD. Mean Vitamin D concentration was $10.04 \pm 6.03 \mathrm{ng} / \mathrm{dl}$. Vitamin $D$ concentration was lower among women living in urban areas $(P=0.001)$ and having lower sun exposure time $(P=0.013)$. Vitamin $D$ levels showed negative correlation with socioeconomic score $(\rho=-0.131 ; P=0.023)$ and BMI $(\rho=-0.112 ; P=0.05)$. In placebo group, women with VDD had longer duration of labor than Vitamin $D$ replete ones $(P=0.031)$. No significant difference was observed between two groups with respect to maternal and fetal outcomes. No adverse effects were observed. Conclusion: VDD is highly prevalent among pregnant women. It is associated with significantly longer duration of labor.

\section{Access this article online}

Website:

http://nepjol.info/index.php/AJMS DOI: 10.3126/ajms.v13i2.40639

E-ISSN: 2091-0576

P-ISSN: 2467-9100

Copyright (c) 2022 Asian Journal of Medical Sciences

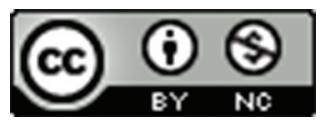

This work is licensed under a Creative Commons Attribution-NonCommercial 4.0 International License.

Key words: Predictors; Pregnancy outcome; Vitamin D deficiency; Vitamin D supplementation

\section{INTRODUCTION}

Prevalence of Vitamin D deficiency (VDD) in pregnancy is variable across the world. ${ }^{1-3}$ Some of the studies have reported high prevalence even in sun-rich countries like India which is situated between $8^{\circ}$ and $37^{\circ} \mathrm{N}$ latitudes..$^{4-8}$
Gradually, it has been realized that effects of Vitamin D are not limited to the maintenance of calcium homeostasis. Hence, implications of VDD in pregnancy may not be limited to effect on maternal and fetal skeletal integrity. Various studies have found association between VDD and adverse outcome of pregnancy. High prevalence, health 
implications of VDD, and availability of simple treatment provide enough rationale for testing all pregnant women for VDD but financial constraints discourage this. ${ }^{9}$ Hence, it is necessary find simple and convenient indicators that could serve as surrogate markers for VDD.

Optimum serum concentration of Vitamin D in pregnancy and dose of routine supplementation have been a matter of debate. VDD has been mostly defined as serum concentration below $20 \mathrm{ng} / \mathrm{ml}$. Institute of Medicine recommends dietary allowance of $600 \mathrm{IU} / \mathrm{d}$ of Vitamin D for pregnant women to attain this level..$^{10} \mathrm{On}$ the other hand, it has been observed that serum level of parathormone starts rising when serum level of Vitamin $\mathrm{D}$ falls below $30 \mathrm{ng} / \mathrm{ml}$. Hence, Endocrine Society guides the clinicians that pregnant and lactating women may be provided at least 1500-2000 IU/d of Vitamin D to achieve a target serum concentration of $30 \mathrm{ng} / \mathrm{ml}^{2}{ }^{2}$ Vitamin D supplementation in the dose of 800-1600 IU/day during pregnancy has not been found to bring significant change in serum Vitamin D level. ${ }^{11}$

Vitamin D receptors as well as $1 \alpha$-hydroxylase are expressed in both decidua and trophoblast cells in the first trimester and serum concentration of $1,25-(\mathrm{OH})_{2} \mathrm{D}$ increases beyond usual regulatory control. ${ }^{12,13}$ Role of Vitamin D in extraskeletal benefits in pregnancy has been attributed to its immunomodulatory properties that allow deeper trophoblastic invasion into spiral arteries.

Cochrane review concluded that women who receive Vitamin D supplements have higher maternal and neonatal serum levels. ${ }^{14}$ Many cross-sectional and prospective studies have shown association between VDD in pregnancy and adverse outcome. There is a paucity of well-designed randomized control trials (RCTs) to study the effect of supplementation in preventing adverse outcome because of inherent ethical issue of depriving women (among those randomized to placebo group) of their recommended daily dose of Vitamin D in pregnancy. Hence, we planned this RCT to study the effect of higher dose of Vitamin D on pregnancy outcome without depriving any participant of her recommended daily dose of Vitamin D.

Aims and objectives

To know the prevalence of Vitamin D deficiency among pregnant women and to study the effect of Vitamin D supplementation on maternal and fetal outcomes.

\section{MATERIALS AND METHODS}

This double-blind randomized placebo controlled trial (1:1 allocation) was conducted at a tertiary care center in North India. The study was approved by Institute's Ethics Committee. It was conducted in full compliance with guidelines of Good Clinical Practice and the Helsinki Declaration. The trial was registered with CTRI (www.ctri. nic.in) vide registration number: CTRI/2013/10/004056.

Consecutive pregnant women attending antenatal clinic were explained about the study and invited to participate. Written informed consent was taken from each woman willing to participate. Women between 18 and 35 years of age at 12-16 weeks of gestation with singleton viable pregnancy were included in the study. Women with medical disorders such as diabetes, hypertension, thyroid disorders, liver, and gallbladder diseases or renal diseases, using medication that is known to affect Vitamin D metabolism (anti-tubercular, anti-epileptics, and theophylline), women with a history of uterine surgery, and women who did not give consent were excluded from the study.

Eligible women were assessed for risk factors such as place of residence (urban or rural), sun exposure time in summer and in winter, body surface area exposed to sunlight, socioeconomic status, ${ }^{15}$ and body mass index (BMI). Skin surface area exposed to sun was considered "large" if exposed area included forearms, hands, and face and it was considered "limited" if sun exposure was confined to only hands and face. Findings were recorded by a blinded observer in pre-designed form.

Blood samples were obtained and stored as sera after centrifugation, in untreated Vacutainer and refrigerated immediately at $-20^{\circ} \mathrm{C}$. Serum $25-\mathrm{OH}$ Vitamin $\mathrm{D}_{3}$ levels were estimated using enzyme-linked immunosorbent assay (ELISA, DIAsource, Belgium). This assay has very low cross-reactivity to the other metabolites of Vitamin $\mathrm{D}_{3}$ and Vitamin $\mathrm{D}_{2}(<0.2 \%)$. VDD was defined as serum concentration of $25(\mathrm{OH})$ vitamin $\mathrm{D}<20 \mathrm{ng} / \mathrm{ml}$. Inter- and intra-assay coefficient of variation was $4.3-9.2 \%$ and $2.5-7.8 \%$, respectively. Relation of gallbladder ejection fraction with VDD was also studied and reported along with risk factors for VDD earlier by our group. ${ }^{16}$

Antenatal investigations were done according to institute's protocol. Vitamin D was started in the dose of $200 \mathrm{IU}$ twice a day along with calcium. After excluding major congenital malformations by ultrasound at 18 weeks, women were randomized using permuted blocks randomization to receive the intervention or identical looking placebo. Intervention group received capsules containing 30,000 IU of Vitamin D (cholecalciferol) each, to be taken orally twice a day for 5 days, making total dose of 300,000 IU. Vitamin D capsules and similar looking placebo capsules were packed in similar looking opaque sealed sachets, each sachet containing two capsules; five such sachets were packed 
into envelops with a serial number from randomization list. The investigator, the subjects, and data entry operator were all blinded to results of Vitamin D estimation and randomization. Compliance was checked by collecting the empty packs at subsequent visit.

All the women were followed up in antenatal outdoor clinic. All the women were provided with phone number of investigators to contact for any emergency and to inform the investigator when they would come for admission for delivery. Details of labor including onset of labor, duration of labor, and mode of delivery were recorded. The baby was assessed by the neonatologist for Apgar score and anthropometry. As the weight, head circumference, and length are affected by gestational age at delivery, z-scores were calculated for these parameters to ensure valid comparison.

Results of Vitamin D estimation and allocation to either group were revealed to the statistician after delivery of the last subject.

Outcome measures were prevalence of VDD and comparison of maternal outcomes in terms of preeclampsia/gestational hypertension, gestational diabetes mellitus, spontaneous preterm labor, gestational age at delivery and mode of delivery, duration of labor, and neonatal outcomes such as neonatal birth weight, head circumference, crown heel length, neonatal Apgar score at $5 \mathrm{~min}$, and admission to neonatal intensive care unit (NICU)/neonatal nursery between the intervention and placebo groups.

\section{RESULTS}

\section{Participants}

A total of 364 women were invited to participate. Out of these, 44 women declined to participate. Sixteen women were excluded due to fetal malformations $(n=8)$ and medical or surgical disorders $(\mathrm{n}=8)$ (Figure 1). Mean age was $24.8 \pm 3.1$ years. Mean BMI was $21.8 \pm 3.4 \mathrm{~kg} / \mathrm{m}^{2}$.

\section{Prevalence and predictors of VDD}

Of these 304 women, 280 (92\%) had Vitamin D deficiency. Median Vitamin D level of whole cohort was $7.9 \mathrm{ng} /$ $\mathrm{ml}$ (IQR 5.7, 12). One hundred and ninety-eight women $(65 \%)$ had severe VDD (serum 25-OH Vitamin D level $<10 \mathrm{ng} / \mathrm{ml})$. Women residing in urban areas $(\mathrm{P}<0.001)$, having limited skin area exposed to sun $(\mathrm{P}=0.03)$ and sun exposure time of $\leq 30 \mathrm{~min}$ in summer $(\mathrm{P}=0.013)$ and $\leq 90 \mathrm{~min}$ in winter $(\mathrm{P}=0.013)$, had significantly lower Vitamin D level (Figure 2). Vitamin D levels showed positive correlation with sun exposure time in summer $(\rho=0.161 ; P=0.005)$ and winter months $(\rho=0.211 ; P<0.001)$ and negative correlation with socioeconomic score $(\rho=-0.131 ; \mathrm{P}=0.023)$ and BMI $(\rho=-0.112 ; \mathrm{P}=0.05) .{ }^{16}$ Women with VDD had lower median calcium levels than those with normal Vitamin D $(8.9 \mathrm{mg} / \mathrm{dl}$ [IQR $8.6,9.1]$ vs. $9.3 \mathrm{mg} / \mathrm{dl}$ [IQR 8.9, 9.4]; $\mathrm{P}=0.03)$.

Effect of VDD and Vitamin D supplementation on maternal and fetal outcome

Out of 304 eligible women, seven were excluded because they did not return timely (till 20 weeks) for intervention. Finally, 297 women were randomized into two groups. One hundred and fifty-one women were allocated to intervention group and 146 to placebo group (Figure 1). There was no difference between the two groups with respect to demographic profile and Vitamin D level (Table 1). Six and 10 women from each respective group did not come to our institute for delivery mainly due to social reasons, hence, considered to be lost to follow-up. Most of these had migrated to their parents' home in the third trimester for delivery and postpartum care.

\section{Maternal outcome}

We did not find significant difference in incidence of preeclampsia, gestational diabetes mellitus, and gestational age at delivery between the intervention and placebo groups (Table 2). Mode of delivery was also similar in two groups. Among the Vitamin D deficient women (serum level $<20 \mathrm{ng} / \mathrm{ml}$ ), those who were assigned to placebo group (did not receive intervention) had longer duration of labor than those who were Vitamin D replete at baseline $(8.23 \pm 4.31 \mathrm{~h}$ vs. $5.59 \pm 2.71 \mathrm{~h} ; \mathrm{P}=0.031)$. Within the placebo group, duration of labor had inverse relation with serum 25-OH Vitamin $\mathrm{D}(\mathrm{r}=-0.210 ; \mathrm{P}=0.027)$.

\section{Fetal outcome}

The median weight-for-gestational age, head circumference, crown-heel length, Apgar score at $5 \mathrm{~min}$ of life, and admission to NICU were not significantly different between the two groups. Fetal malformations were observed in three newborns in the intervention group (club foot in one and polydactyly in two babies) and in two newborns in the placebo group (cleft palate and hydrocephalus). One of the two abortions in placebo group was induced due to fetal malformation (hydrocephalus) and the other one was due to pre-viable rupture of membranes.

\section{DISCUSSION}

Having defined VDD as serum Vitamin D level of $<20 \mathrm{ng} /$ $\mathrm{ml}$, we found a very high prevalence of VDD (92\%) among pregnant Indian women. The previous studies from the region ${ }^{46}$ have also reported high prevalence among pregnant women. This indicates that it has not changed 


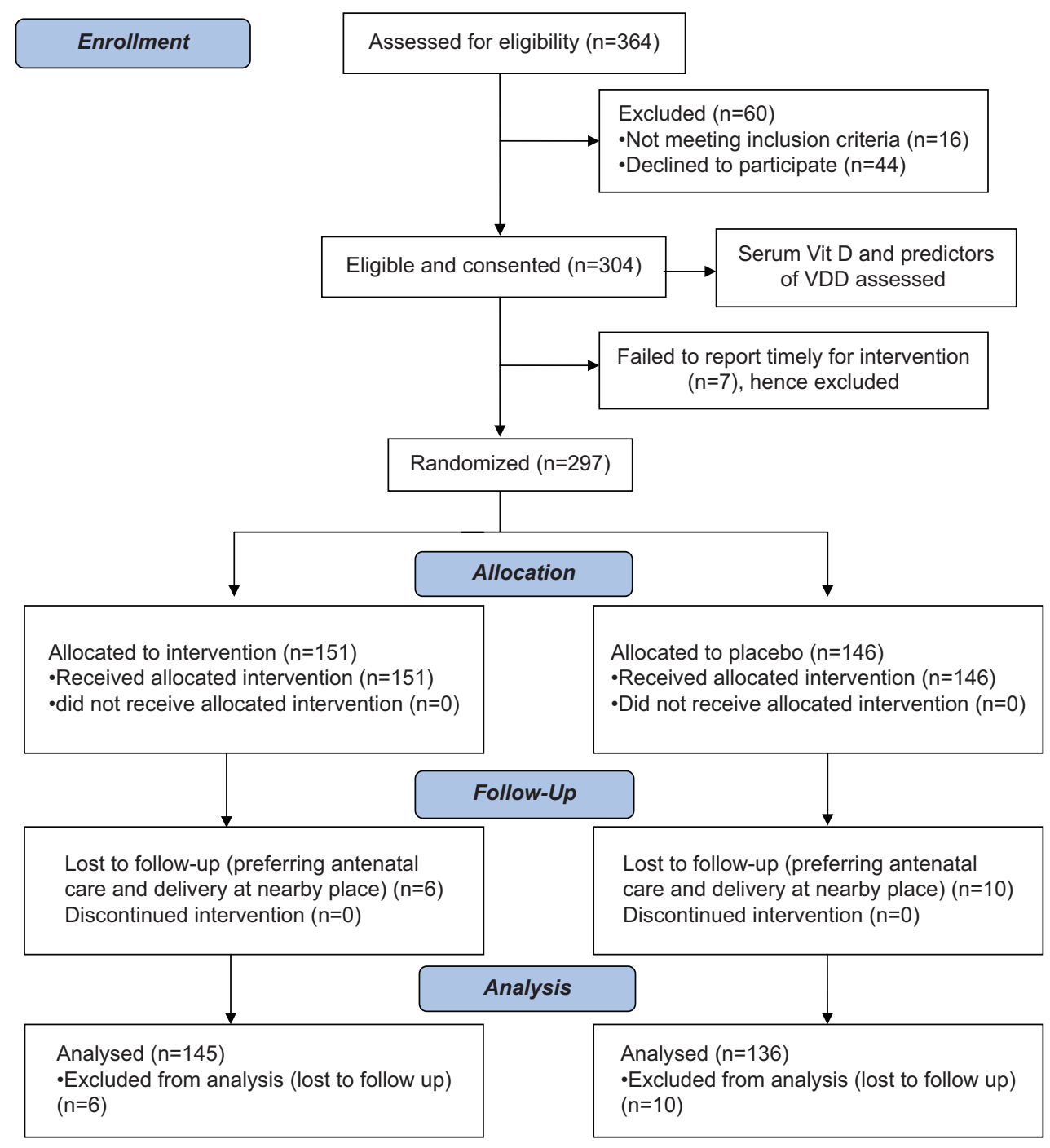

Figure 1: Diagram showing flow of participants. VDD: Vitamin D deficiency

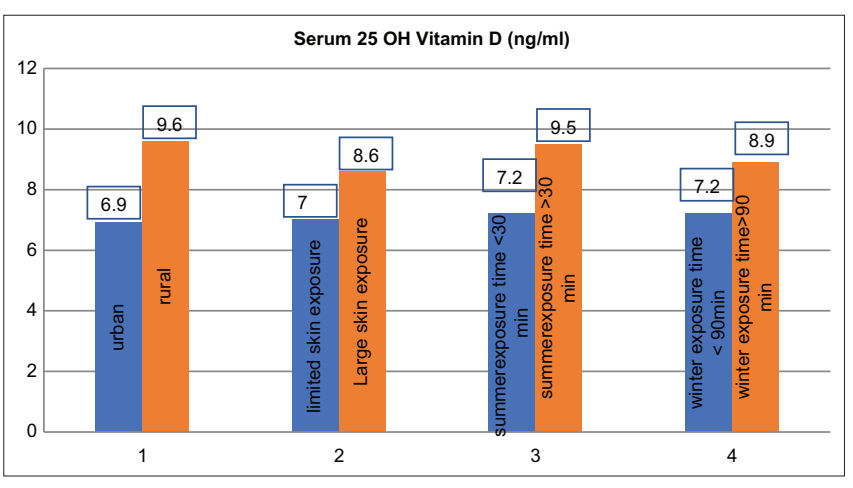

Figure 2: Comparison of Vitamin $D$ levels across potential predictors of Vitamin D deficiency. $\mathrm{ng} / \mathrm{ml}$ : Nanogram per milliliter

significantly overtime. Most of the women $(65 \%)$ in our study had severe VDD $(<10 \mathrm{ng} / \mathrm{ml})$.

Serum Vitamin D levels were significantly higher among rural women than urban women likely because of lesser pollution in rural areas or more outdoor activity.
Sun exposure time affected serum Vitamin D levels as longer duration of exposure to sun (for at least $30 \mathrm{~min}$ in summers and $90 \mathrm{~min}$ in winters) resulted in higher serum concentration of Vitamin D. Vitamin D levels are expected to be affected by seasonal variation in our part of the country as geographically it is in subtropical zone. Socioeconomic status and BMI showed inverse relation with serum Vitamin D levels. As the socioeconomic score increased serum Vitamin D level decreased.

Despite significant difference in Vitamin D levels among women belonging to different demographic parameters, it is important to realize that the respective median Vitamin D concentrations were low (Figure 2). It is difficult to comment with confidence whether presence of these demographic features can become the basis of diagnosis and treatment of VDD without actual testing.

Vitamin D deficient women had significantly lesser serum calcium levels as compared to Vitamin D replete 
women. Optimal calcium levels are important for muscle function. We observed longer duration of labor among the Vitamin D deficient women who did not receive Vitamin D supplementation, that is, the women who were randomized to placebo arm. This can be explained by poor muscle function attributable to lower calcium level in Vitamin D deficient women.

\begin{tabular}{|c|c|c|}
\hline Parameter & $\begin{array}{c}\text { Vitamin } D \\
\text { supplementation } \\
\text { group }(n=151)\end{array}$ & $\begin{array}{l}\text { Placebo } \\
\text { group } \\
(n=146)\end{array}$ \\
\hline \multicolumn{3}{|l|}{ Parity; n (\%) } \\
\hline Nulliparous & $122(80.8)$ & $105(71.9)$ \\
\hline \multicolumn{3}{|l|}{$\begin{array}{l}\text { Socioeconomic status; } \\
\text { n (\%) }\end{array}$} \\
\hline Upper and upper-middle & $54(35.8)$ & $61(41.7)$ \\
\hline Lower-middle and middle & $64(42.38)$ & $52(35)$ \\
\hline Upper-lower and lower & $33(21.85)$ & $33(22.60)$ \\
\hline \multicolumn{3}{|l|}{ Residence; n (\%) } \\
\hline Rural & $66(43.7)$ & $67(45.9)$ \\
\hline Urban & $85(56.3)$ & $79(54.1)$ \\
\hline BMI; (mean \pm S. D) kg/m² & $21.6 \pm 3.3$ & $22.0 \pm 3.5$ \\
\hline $\begin{array}{l}\text { Median Vitamin D; (IQR) } \\
(\mathrm{ng} / \mathrm{ml})\end{array}$ & $7.8(5.7-11.5)$ & $8.6(5.7-12.8)$ \\
\hline
\end{tabular}

We did not find significant difference in maternal and fetal outcome between Vitamin D supplementation group and placebo group. Cochrane review also concluded that Vitamin D supplementation in pregnancy improves serum Vitamin D level, but further investigation is needed to see whether this converts into better pregnancy outcome or not. ${ }^{14}$ Decline in $25(\mathrm{OH}) \mathrm{D}$ concentration by $50 \mathrm{nmol} /$ liter was found to double the risk of preeclampsia (adjusted odds ratio, 2.4) in one study. ${ }^{17}$ Further, serum 25(OH) D level (median $18 \mathrm{ng} / \mathrm{ml}$ ) was found to be lesser among the women with early-onset (before 34 weeks) severe preeclampsia as compared to healthy controls (median $32 \mathrm{ng} / \mathrm{ml}) .{ }^{18}$ Lower Vitamin D levels (24.2 ng/ml vs. $30.1 \mathrm{ng} / \mathrm{ml}$ ) have been found to be associated with risk of GDM also. ${ }^{19}$ Women with GDM were found to have 2.7 times more chance of having VDD in one study. ${ }^{20}$

However, causality cannot be ascertained from observational studies. RCT would be needed to establish cause and effect relation between VDD and adverse pregnancy outcome but these cannot be carried out due to inherent ethical issues related to depriving a woman of her daily recommended Vitamin D supplement. Cochrane review does not take into account the findings of Hollis et al., ${ }^{21}$ due to lack of controls. Hollis et al., found significant difference in preeclampsia (2.6\% and $8.1 \%)$ and primary cesarean section rate $(14 \%$ and $25 \%)$ between

Table 2: Comparison of maternal and fetal outcome between two groups

\begin{tabular}{|c|c|c|c|}
\hline Parameter & Vitamin D & Placebo & $P$ value \\
\hline Antenatal complications & $(n=151)$ & $(n=146)$ & \\
\hline Gestational diabetes mellitus (n) & 5 & 5 & 0.5 \\
\hline Fasting plasma glucose (mean \pm S.D.) mg/dl & $76.8 \pm 6.86$ & $76.0 \pm 9.14$ & 0.389 \\
\hline Preeclampsia/gestational hypertension (no.) & 40 & 40 & 0.6 \\
\hline Labor and delivery & $(n=145)$ & $(n=134)$ & \\
\hline Gestation at delivery (days) (mean \pm S.D.) & $268 \pm 10.7$ & $268 \pm 9.16$ & 0.652 \\
\hline Induced labor (no.) & 45 & 48 & 0.2 \\
\hline Spontaneous preterm labor $(\mathrm{n})$ & 8 & 6 & 0.6 \\
\hline Duration of labor (hours) (mean \pm S.D.) & $8.8 \pm 5.6$ & $8.7 \pm 4.3$ & 0.105 \\
\hline \multicolumn{4}{|l|}{ Mode of delivery $(n)$} \\
\hline Vaginal delivery & 102 & 104 & \\
\hline Instrumental & 8 & 12 & \\
\hline Cesarean section (total) & 35 & 18 & \\
\hline Cesarean section in labor & 30 & 16 & \\
\hline \multicolumn{4}{|l|}{ Neonatal outcome } \\
\hline Weight-for-gestational-age & $-0.81(-1.37,+0.02)$ & $-0.62(-1.35,+0.027)$ & 0.903 \\
\hline \multicolumn{4}{|l|}{ z-score [median $\left(1^{\text {st }}, 3^{\text {rd }}\right.$ quartile $\left.)\right]$} \\
\hline Head circumference (mean \pm S.D.) $\mathrm{cm}$ & $34.09 \pm 1.51$ & $34.09 \pm 1.2$ & 0.989 \\
\hline Head circumference $z$-score median ( $1^{\text {st }}, 3^{\text {rd }}$ quartile $)$ & $0.05(-0.26,+0.53)$ & $0.21(-0.29,+0.53)$ & 0.830 \\
\hline Length(mean \pm S.D.) cm & $49.77 \pm 2.46$ & $49.48 \pm 2.01$ & 0.338 \\
\hline Length z-score [median ( $1^{\text {st }}, 3^{\text {rd }}$ quartile $)$ ] & $-0.09(-0.46,+0.34)$ & $-0.13(-0.58,0.21)$ & 0.250 \\
\hline Apgar at 5 min median ( $1^{\text {st }}, 3^{\text {rd }}$ quartile $)$ & $9(9,9)$ & $9(9,9)$ & 0.4 \\
\hline Malformation $(n)$ & 3 & 2 & 0.5 \\
\hline Live born & 145 & 133 & 0.2 \\
\hline Stillborn & 0 & 1 & \\
\hline Abortus & 0 & 2 & \\
\hline Jaundice requiring phototherapy (no.) & 20 & 13 & 0.3 \\
\hline NICU/NNN admission $(n)$ & 5 & 4 & 0.8 \\
\hline
\end{tabular}


higher dose and conventional daily dose of Vitamin D. However, it is important to note that they observed difference in these parameters between the two arms $4000 \mathrm{IU} / \mathrm{d}$ (cumulative dose of 756,000 IU) versus $400 \mathrm{IU} / \mathrm{d}$ (cumulative dose 75,600 IU) of Vitamin D from 12 weeks. No difference was observed between intermediate supplementation dose group (2000 IU/day) and $400 \mathrm{IU} / \mathrm{d}$ group. In our study also, conventional dose of $400 \mathrm{IU} / \mathrm{d}$ was given to all women. Overall compliance with routine daily prenatal supplements (iron and calcium) is not good among our antenatal women. Hence, we chose to give supplement at one time and also collected empty packs in subsequent visit. In our study, the difference in the cumulative dose between the two groups was 300,000 IU that was much lower than the cumulative dose given by Hollis et al. This dose may not have been sufficient to bring about the difference in severely deficient cohort. Considering the pathogenesis of preeclampsia from early gestation, supplementation at an earlier gestation (in the first trimester) rather than at 18-20 weeks may have made a difference.

Hollis et al., also found a significant reduction in cesarean section rate in high-dose supplementation group. ${ }^{21}$ We did not find significant difference in mode of delivery though duration of labor was longer in Vitamin D deficient women within the placebo group. We did not find significant difference in duration of labor among women assigned to Vitamin D versus placebo group.

Birth weight and gestational age are the two important determinants of neonatal outcome. Data from three trials involving 463 women suggest that women who receive Vitamin D supplements during pregnancy less frequently have baby with birth weight below $2500 \mathrm{~g}$ but this difference was of borderline significance ${ }^{14}$ (RR 0.48 ; 95\% CI 0.23-1.01). The dose of supplementation in these studies was 56,000$1,200,000$ IU. Some of the earlier studies have reported greater length and head circumference of the offspring of women receiving higher dose of Vitamin $\mathrm{D}^{22}$ while others did not. ${ }^{4}$ Another meta-analysis did not observe a significant effect in pooled analysis of small for gestational age babies. ${ }^{23}$ In our study, weight-for-gestational age z-scores and other anthropometric parameters were not significantly different in two groups but the highest centile of birth weight was higher $\left(97^{\text {th }}\right)$ in the intervention group than the placebo group $\left(89^{\text {th }}\right)$. Relation between preterm delivery and VDD has also not been observed consistently across various studies. ${ }^{23-25}$ Even higher dose of Vitamin D supplementation has not made a significant difference in this parameter ${ }^{21}(\mathrm{P}=0.4)$.

\section{Strengths}

All investigators were blinded for Vitamin D levels and group allocation. Thus, ascertainment biases, differential recall biases, and selection biases are unlikely. We addressed all the outcomes pertaining to maternal and fetal health.
Large sample size and small "lost to follow-up" fraction is another strong point. The main question that whether there is any advantage of supplementing Vitamin D over and above the current practice of $400 \mathrm{IU} / \mathrm{d}$ is well addressed as the entire cohort received the currently recommended dose.

\section{Limitations of the study}

Supplementation with 300,000 IU must have improved the Vitamin D status but may not have corrected the deficiency. Post-intervention-Vitamin D level could not be checked due to logistic issues. Since both the intervention and placebo groups received the routine dose, the difference in cumulative dose between two groups got reduced and might this have been the reason for not observing significant difference in outcome.

\section{CONCLUSIONS}

Vitamin D is highly prevalent among pregnant women. It is associated with significantly longer duration of labor. In vitamin $\mathrm{D}$ deficient pregnant women, additional supplementation with 300,000 IU of vitamin D does not affect the maternal and fetal outcome significantly. However, higher dose of vitamin D is safe in pregnancy.

\section{ACKNOWLEDGMENT}

Council of Scientific and Industrial Research, India.

\section{REFERENCES}

1. Holick MF. Vitamin D deficiency. N Engl J Med. 2007;357(3):266-281.

https://doi.org/10.1056/NEJMra070553

2. Holick MF, Binkley NC, Bischoff-Ferrari HA, Gordon CM, Hanley DA, Heaney RP, et al. Evaluation, treatment, and prevention of Vitamin $\mathrm{D}$ deficiency: An endocrine society clinical practice guideline. J Clin Endocrinol Metab. 2011;96(7):1911-1930.

https://doi.org/10.1210/jc.2011-0385

3. Bodnar LM, Simhan HN, Powers RW, Frank MP, Cooperstein E and Roberts JM. High prevalence of Vitamin D insufficiency in black and white pregnant women residing in the northern United States and their neonates. J Nutr. 2007;137(2):447-452. https://doi.org/10.1093/jn/137.2.447

4. Farrant HJ, Krishnaveni GV, Hill JC, Boucher BJ, Fisher DJ, Noonan K, et al. Vitamin D insufficiency is common in Indian mothers but is not associated with gestational diabetes or variation in newborn size. Eur J Clin Nutr. 2009;63(5):646-652. https://doi.org/10.1038/ejcn.2008.14

5. Goswami R, Kochupillai N, Gupta N, Goswami D, Singh N, Dudha A, et al. Presence of 25(OH) D deficiency in a rural North Indian village despite abundant sunshine. J Assoc Physicians India. 2008;56:755-757.

6. Sachan A, Gupta R, Das V, Agarwal A, Awasthi PK and Bhatia V. High prevalence of Vitamin-D deficiency among pregnant women and their newborns in northern India. Am J Clin Nutr. 
2005;81(5):1060-1064

https://doi.org/10.1093/ajcn/81.5.1060

7. Sahu M, Bhatia V, Aggarwal A, Rawat V, Saxena P, Pandey A, et al. Vitamin $D$ deficiency in rural girls and pregnant women despite abundant sunshine in Northern India. Clin Endocrinol (Oxf). 2009;70(5):680-684.

https://doi.org/10.1111/j.1365-2265.2008.03360.x

8. Jani R, Palekar S, Munipally T, Ghugre P and Udipi S. Widespread 25-hydroxyvitamin $D$ deficiency in affluent and nonaffluent pregnant Indian women. Biomed Res Int. 2014;2014:892162. https://doi.org/10.1155/2014/892162

9. Sattar N, Welsh P, Panarelli M and Forouhi NG. Increasing requests for Vitamin D measurement: Costly, confusing, and without credibility. Lancet. 2012;379(9811):95-96.

https://doi.org/10.1016/S0140-6736(11)61816-3

10. Ross AC, Manson JE, Abrams SA, Aloia JF, Brannon PM, Clinton SK, et al. The 2011 report on dietary reference intakes for calcium and Vitamin $D$ from the institute of medicine: What clinicians need to know. J Clin Endocrinol Metab. 2011;96(1):53-58. https://doi.org/10.1210/jc.2010-2704

11. Datta S, Alfaham M, Davies DP, Dunstan F, Woodhead S, Evans $\mathrm{J}$, et al. Vitamin $\mathrm{D}$ deficiency in pregnant women from a non-European ethnic minority population-an interventional study. BJOG. 2002;109(8):905-908.

https://doi.org/10.1111/j.1471-0528.2002.01171.x

12. Zhender D, Bland R, Williams MC, McNinch RW, Howie AJ, Stewart PM, et al. Extrarenal expression of 25-hydroxyvitamin d(3)-1 alpha-hydroxylase. J Clin Endocrinol Metab. 2001;86(2):888-894.

https://doi.org/10.1210/jcem.86.2.7220

13. Norman AW. Vitamin D receptor: New assignments for an already busy receptor. Endocrinology. 2006;147(12):5542-5548. https://doi.org/10.1210/en.2006-0946

14. De-Regil LM, Palacios C, Ansary A, Kulier R and Peña-Rosas JP. Vitamin D supplementation for women during pregnancy. Cochrane Database Syst Rev. 2012;2(2):CD008873. https://doi.org/10.1002/14651858.CD008873.pub2

15. Sharma R. Kuppuswamy's socioeconomic status scale revision for 2011 and formula for real-time updating. Indian J Pediatr. 2012;79(7):961-962.

https://doi.org/10.1007/s12098-011-0679-3

16. Singla R, Dutta U, Aggarwal N, Bhadada SK, Kochhar R and Dhaliwal LK. Vitamin-D deficiency is associated with gallbladder stasis among pregnant women. Dig Dis Sci. 2015;60(9):2793-2799. https://doi.org/10.1007/s10620-015-3678-9

17. Bodnar LM, Catov JM, Simhan HN, Holick MF, Powers RW, Roberts JM. Maternal Vitamin D deficiency increases the risk of preeclampsia. J Clin Endocrinol Metab. 2007;92(9):3517-3522. https://doi.org/10.1210/jc.2007-0718

18. Robinson CJ, Alanis MC, Wagner CL, Hollis BW and Johnson DD. Plasma 25-hydroxyvitamin $D$ levels in early-onset severe preeclampsia. Am J Obstet Gynecol. 2010;203(4):366.e1-6. https://doi.org/10.1016/j.ajog.2010.06.036

19. Zhang C, Qiu C, Hu FB, David RM, van Dam RM, Bralley A, et al. Maternal plasma 25-hydroxyvitamin D concentrations and the risk for gestational diabetes mellitus. PLoS One. 2008;3(11):e3753.

https://doi.org/10.1371/journal.pone.0003753

20. Soheilykhah S, Mojibian M, Rashidi M, Rahimi-Saghand $S$ and Jafari F. Maternal Vitamin D status in gestational diabetes mellitus. Nutr Clin Pract. 2010;25(5):524-7. https://doi.org/10.1177/0884533610379851

21. Hollis BW, Johnson D, Hulsey TC, Ebeling M and Wagner CL. Vitamin D supplementation during pregnancy: Double-blind, randomized clinical trial of safety and effectiveness. J Bone Miner Res. 2011;26(10):2341-2357.

https://doi.org/10.1002/jbmr.463

22. Morley R, Carlin JB, Pasco JA and Wark JD. Maternal 25-hydroxyvitamin $\mathrm{D}$ and parathyroid hormone concentrations and offspring birth size. J Clin Endocrinol Metab. 2006;91(3):906-912.

https://doi.org/10.1210/jc.2005-1479

23. Thorne-Lyman A, Fawzi WW. Thorne-Lyman A and Fawzi WW. Vitamin $D$ during pregnancy and maternal, neonatal and infant health outcomes: A systematic review and meta-analysis. Paediatr Perinat Epidemiol. 2012;26(Suppl 1):75-90. https://doi.org/10.1111/j.1365-3016.2012.01283.x

24. Baker AM, Haeri S, Camargo CA, Stuebe AM and Boggess KA. A nested case-control study of first-trimester maternal Vitamin D status and risk for spontaneous preterm birth. Am J Perinatol. 2011;28(9):667-672.

https://doi.org/10.1055/s-0031-1276731

25. Mehta S, Hunter DJ, Mugusi FM, Spiegelman D, Manji KP, Giovannucci EL, et al. Perinatal outcomes, including motherto-child transmission of HIV, and child mortality and their association with maternal Vitamin D status in Tanzania. J Infect Dis. 2009;200(7):1022-1030.

https://doi.org/10.1086/605699

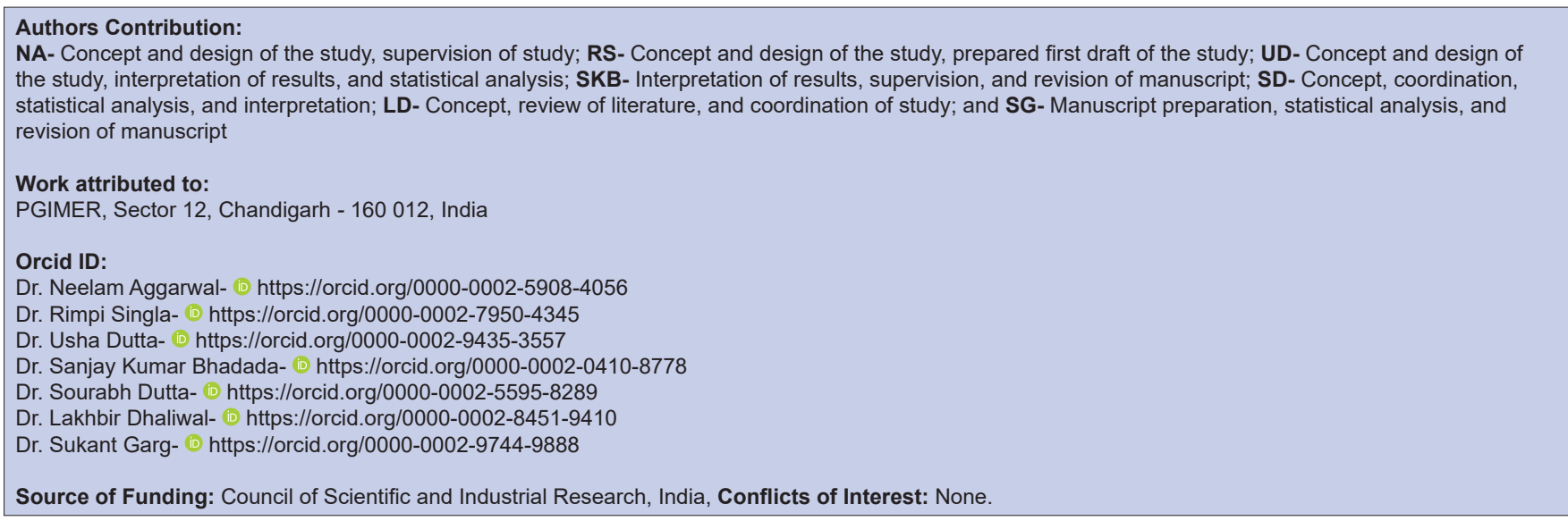

